\title{
COVID-19: UMA ABORDAGEM PREVENTIVA PARA ODONTOLOGIA
}

COVID-19: A PREVENTIVE APPROACH TO DENTISTRY

\section{Alonso Alves de Araujo}

Centro Universitário Doutor Leão Sampaio - UNILEÃO *E-mail: alonsoaraujoodt@hotmail.com

\section{RESUMO}

Este trabalho descreve uma revisão narrativa de literatura recente, abordando o atual conhecimento sobre um novo surto de pneumonia de origem Chinesa que se tornou assunto de saúde publica mundial, o vírus SARS-CoV-2 causador da doença COVID-19, de rápida disseminação, através da saliva, tosse e espirro. Devido à alta exposição da equipe odontológica a esses fluídos orgânicos através do aerossol produzido no atendimento clinico, esse trabalho tem como objetivo informar a comunidade científica e a população em geral e tornar possível, especificamente, que - Cirurgião-Dentista possa identificar casos suspeitos e, principalmente, adotar medidas preventivas de contaminação no serviço odontológico através da biossegurança. Foi realizada uma revisão narrativa de literatura no período de 14 de maio a 15 de outubro de 2020 nos bancos de dados Pub Med, BVS, Scielo e Lilacs. Foram considerados artigos completos de acesso livre, publicados nos últimos cinco anos. Utilizaram-se os seguintes descritores nos idiomas português e inglês: COVID-19 odontologia, coronavírus odontologia, aerossol COVID-19 dentista, biossegurança COVID-19. Os registros encontrados tiveram título e resumo lidos para confirmação de pertinência temática e seleção de artigos para leitura completa. Os trabalhos lidos na íntegra cujo tema foi considerado pertinente foram incluídos e integram a revisão bibliográfica $(n=11)$. Foram excluídos da pesquisa todos os trabalhos que não atenderam aos critérios de inclusão estabelecidos. A revisão demonstrou que em momentos de surtos de doenças, surgem novos desafios aos quais os profissionais devem responder com maior cuidado buscando informações atualizadas para reconhecer os riscos que desafiam a biosegurança no atendimento odontológico.

Palavras-chave: COVID-19; Coronavírus; Odontologia.

\section{ABSTRACT}

This paper describes a systematic review of recent literature, addressing current knowledge about a new Chinese pneumonia outbreak that has become a worldwide public health issue, the rapidly spreading SARS-CoV-2 virus, the disease COVID-19, through saliva, coughing and sneezing. Due to the high exposure of the dental team to these organic fluids through the aerosol produced in clinical care, this work aims to inform the scientific community and the population in general and make it possible, specifically, for the Dental Surgeon to identify suspicious cases and, mainly, to adopt preventive measures of contamination in the dental service through biosafety. A systematic literature review was carried out from May 14 to october 15, 2020 in the Pub Med, VHL, Scielo and Lilacs databases. Full open access articles published in the last five years were considered. The following descriptors were used in Portuguese and English: COVID-19 dentistry, coronavirus dentistry, aerosol COVID-19 dentist, biosafety COVID-19. The records found had a title and abstract read to confirm the thematic pertinence and selection of articles for complete reading. Papers read in full whose topic was considered relevant were included and included in the bibliographic review $(n=11)$. All works that did not meet the established inclusion criteria were excluded from the research. The review showed that in times of disease outbreaks, new challenges arise that professionals must respond with greater care, seeking updated information to recognize the risks that challenge biosafety in dental care.

Keyword: COVID-19; Coronavirus; Dentistry. 


\section{INTRODUÇÃO}

Em dezembro de 2019, foi notificado um surto de pneumonia em Wuhan, China sem causa diagnosticada. Os casos tinham como sugestão da causa, um patógeno que poderia ser transmitido de animais para seres humanos, logo tomou uma maior proporção e foi possível a trasmissão entre humanos. Através de estudos em laboratório, o vírus foi detectado e recebeu o nome de SARS-CoV-2 e a doença foi chamada de COVID-19 (GE et al, 2020).

Com base nos dados recuperados da Organização Mundial da Saúde (OMS), foram notificados 38.394.169 casos confirmados, com 1.089.047 mortes em todo o mundo, até a data dessa pesquisa. Desde o início dos casos, o numero é atualizado diariamente em uma proporção que se mostra cada vez maior. (WHO, 2020).

A transmissão é feita através de gotículas produzidas pelo individuo infectado que apresente ou não os sinais clínicos da doença COVID-19. Pacientes na fase assintomática da doença podem transmitir o vírus. $\mathrm{O}$ contágio pode ocorrer através de uma aproximação interpessoal, contato com superfícies contaminadas ou partículas no ar, sendo necessário adotar, portanto, medidas de prevenção e higienização adequada das mãos e ambientes (GIUDICE, 2020).

Os cuidados com as práticas de biossegurança mostram-se indispensáveis para um atendimento feito de maneira segura, evitando a possibilidade de transmissão entre o paciente e a equipe de saúde bucal. Devido à proximidade, como também à produção de aerossóis e exposição a fluidos orgânicos como saliva e sangue, os cuidados com a prática se tornam ainda mais necessários (TUÑAS et al, 2020).

Este artigo tem como finalidade trazer uma série de informações existentes até o momento que seja pertinente ao novo Coronavírus, suas manifestações clínicas, vias de contágio e prevenção. As informações aqui presentes estão sujeitas a sofrerem alterações cientificas ou legislativas, pois enfrentamos um vírus desconhecido. É aconselhável manter-se atualizado sobre a doença e suas diferentes rotas de infecção, como também seguir as medidas de prevenção recomendadas pela organização mundial de saúde (RODRÍGUEZ et al, 2020).

\section{METODOLOGIA}

Tratou-se de um estudo de revisão narrativa da literatura com caráter qualitativo. Foram selecionados para leitura completa: Pub Med (10), BSV (8), Scielo (3), Lilacs (0). Os artigos cuja pertinência temática foi confirmada na leitura completa fizeram parte da revisão, totalizando 11 artigos.

Quanto aos critérios adotados para a inclusão neste estudo, foram utilizados apenas artigos com disponibilidade para leitura completa, publicados nos últimos cinco anos (2015 a outubro de 2020). Foram feitas as leituras dos títulos e dos resumos de todos os registros encontrados para selecionar os artigos pertinentes para leitura completa.

Os artigos que não obedeceram a esses critérios foram excluidos. Outro critério de exclusão adotado foi a exclusão de artigos de opinião, teses e dissertações. Também foram realizadas buscas em periódicos especializados e disponíveis online, considerando o mesmo período de tempo: Agência de Vigilância Sanitária (ANVISA) e OMS. Foram feitas pesquisas nas bases de dados Pub Med, BVS, Scielo e Lilacs com os descritores nos idiomas Português e Inglês, conforme tabela 1.

Tabela 1. Descritores usados nas bases de dados, nos idiomas português e inglês

\section{BASE DE DADOS}

\section{PORTUGUÊS}

COVID-19 odontologia

\section{DESCRITORES}

Coronavírus odontologia

Pub Med, BVS, Scielo e Lilacs.
COVID-19 dentistry

\section{INGLÊS}

Coronavirus dentistry
Aerossol COVID-19 dentista

Biossegurança COVID-19

Aerosol COVID-19 dentist

Biosafety COVID-19 


\section{RESULTADOS}

\section{PROGRESSÃO DA DOENCA}

Foram feitos registros em dezembro 2019 de surtos de pneumonia em Wuhan, Hubei e China sem causa diagnosticada (QUN et al.,2020). Após um mês do aumento de casos, foi possivel isolar em laboratório o vírus causador de uma sindrome respitatória aguda grave (SARS-CoV-2) que se diferenciava de todos os virus respiratórios comuns já identificados em estudos laboratoriais como SARS-CoV, MERS-CoV, gripe aviária e gripe (ZHU et al., 2020).

Desde que o surto teve inicio, a china adotou medidas de saúde pública para combater e interromper as rotas de transmissão, tratando com atenção os suspeitos confirmados. Em 30 de janeiro de 2020 os casos aumentaram de forma alarmante e a OMS declarou estado de emergência na saúde púbica de interesse internacional (PHEIC) atribuindo o nome de COVID-19 a esse vírus. Apesar da grande atenção ao novo COVID-19 através de estudos, o que se sabe é que seu modo de transmição é feito por vias de contato através de goticulas, não sendo descartadas a transmissão aérea como via de contágio (QUN et al. 2020).

O novo SARS-CoV-2 pode ter como sintomas alterações respiratórias e infecções podendo se espalha mais rapidamente do que os vírus identificados anteriormente a eles. $\mathrm{O}$ vírus tem em sua composição membranosa, formas de espinhos de proteínas que se ligam às células através dos receptores ACE2 (enzima conversora da angiotensina 2). Diz-se que os seres humanos e morcegos são hospedeiros do novo corona virus. Supõe-se que o Pangolim (tamanduá escamoso) seja um hospedeiro intermediário (TUÑAS et al., 2020).

\section{VIAS DE TRASMISSÃO}

A transmissão do COVID-19 é feita entre pessoas através de gotículas produzidas pelo espirro, tosse ou fala. Por esse motivo a organização mundial de saúde preconiza o distanciamento de pelo menos um metro entre as pessoas. As gotículas produzidas pelas pessoas infectadas são capazes de permanecer por dias em superfícies de objetos como tecidos, plásticos, ferro, madeira (OLIVEIRA et al., 2020).

É possível o contágio entre pessoas que tocam superfícies contaminadas e colocam as mãos nos olhos, boca e nariz. Desse modo, é extremamente importante a higienização das mãos com água e sabão ou fazendo uso de álcool gel $70 \%$. A OMS e a Organização PanAmericana de Saúde (OPAS) continuarão a evidenciar descobertas feitas em pesquisas sobre o modo de disseminação do COVID-19 (TUÑAS et al., 2020).
$\mathrm{O}$ vírus pode ser transmitido entre pessoas por meio de contato direto ou indireto, saliva e fluidos orgânicos. Na Alemanha, houve a confirmação de tramissão do vírus por meio de pessoas assintomáticas. Os cuidados com as práticas no atendimento odontológico tornam-se mais evidentes, visto a proximidade de trabalho entre o cirurgião dentista e o paciente, devido à grande produção de fluidos, saliva e sangue propagados através dos aerossóis provenientes do procedimento odontológico (OLIVEIRA et al., 2020).

\section{DESENVOLVIMENTO DOS SINTOMAS}

As manifestações sintomáticas mais comuns observadas em pacientes infectados pelo COVID-19 são febre, tosse seca e cansaço. Em alguns pacientes as manifestações podem apresentar-se com dores, congestão nasal, dor de cabeça, dor de garganta, diarréia, perda de paladar ou olfato, conjuntivite, manifestações em erupções na pele ou descoloração dos dedos das mãos ou dos pés. Essas manifestações são classificadas como leve e se iniciam de forma gradativa (MONTE et al., 2020).

Em algumas pessoas infectadas, os sintomas se apresentam de forma mais branda. O período de incubação entre o momento da exposição e a manifestação dos primeiros sintomas é por volta de cinco a seis dias, podendo ter variações de 1 a 14 dias. Segundo a OMS, os pacientes que entram em isolamento, só podem ser liberados após serem feitos dois testes tendo como resultado negativo, com pelo menos 24 horas de intervalo. Em caso de positivo, o paciente deve permanecer isolado por duas semanas após o fim dos sintomas (MONTE et al., 2020).

\section{REPERCUCÃO ODONTOLÓGICO}

NO

ATENDIMENTO

Os aerossóis e gotículas produzidos no atendimento odontológico são relatados pela literatura como fator primordial para a disseminação do vírus causador da doença COVID-19 através de partículas contaminadas com flúidos orgânicos do paciente, sendo possível que esse vírus se mantenha viavél sobre superfícies por um longo período e até dias, pondo em risco toda a equipe envolvida no atendiemnto odontologico e as demais pessoas que estão no local de atendimento (PEREIRA, 2020).

Os fluidos orais trazem em sua composição partículas orgânicas e bactérias, tendo como principal fonte a placa, cárie e bolsas periodontais. Todavia, devese levar em conta que a boca e a faringe fazem parte de um sistema em conjunto com o nariz, garganta e trato respiratório. A boca sendo componente desse sistema acolhe bactérias do trato respiratório, nariz e garganta. 
Devido à comunicação direta entre a cavidade bucal e o sistema respiratório, é possível a inclusão de vírus e bactérias patogênicas na saliva e fluidos orais. Procedimentos realizados no consultório odontológico que tenham como resultante a produção de aerossóis irão causar a contaminação do ar com esses microrganismos (OLIVEIRA et al., 2020).

$\mathrm{O}$ atendimento odontológico eletivo não emergencial recebeu ordens de suspensão vindas da organização mundial de saúde, tornando viável a procura de atendiemnto apenas em casos de emergência. É evidente a produção de uma nuvem de aerossol que se forma durante o atendimento odontológico, resultante do procedimento com uso de instrumento rotatório, seringa de ar e água ou raspador ultrassônico. Esse aerossol resultante da combinação de fluidos orgânicos do paciente tem potencial de disseminar a doença, que, por sua vez, pode levar à Síndrome Respiratória Aguda Grave (SARS), entre outras doenças possíveis de transmissão pela mesma via de contágio (XIAN et al, 2020).

$\mathrm{O}$ profissional de odontologia deve estar apto a reconhecer casos com suspeita de COVID-19 segundo a quinta edição da Diretriz para o Diagnóstico e Tratamento da nova pneumonia por coronavírus, que foi redigido pela Comissão Nacional de Saúde da Republica Popular da China. O paciente que apresenta sintomas na fase febril aguda, não deve comparecer à consulta odontológica, sendo necessário colocá-lo em quarentena e comunicar ao controle de infecções o mais rápido possível (XIAN et al., 2020).

\section{CONDUTAS PARA ODONTOLÓGICO}

ATENDIMENTO

A triagem do paciente é feita em primeiro momento com uso de um termômetro frontal sem qualquer contato físico, seguido de um questionário que possibilita identificar pacientes com potencial de infecção por COVID-19. O questionário aborda as seguintes perguntas: 1 - Apresentou febre nos últimos 14 dias? 2- Nos últimos 14 dias, apresentou tosse ou dificuldade em respirar? 3Nos últimos 14 dias, fez viagens internacionais ou esteve em bairros com transmissão notificada de COVID-19? 4Teve contato com pessoas confirmadas de COVID-19? 5Entrou em contato com pessoas que fizeram viagem internacional ou que apresentaram febre ou problema respiratório? 6- Duas pessoas próximas a você tiveram sintomas de febre ou problemas respiratórios nos últimos 14 dias? (GILDICE et al., 2020).

Se obtiver resposta "sim" para qualquer uma das perguntas e apresentar temperatura corporal acima de 37,3 - $\mathrm{C}$, o dentista deve adiar o tratamento em até 14 dias e instruir o paciente a ficar em quarentena domiciliar e relatar ao departamento de saúde local qualquer alteração na temperatura ou sintomas respiratórios. Se obtiver resposta "sim" para qualquer uma das perguntas e apresentar temperatura corporal acima de $37,3^{\circ} \mathrm{C}$, o dentista deve imediatamente colocar o paciente em quarentena e acionar o hospital da saúde local (GILDICE et al., 2020).

Paciente sem suspeita para COVID-19 e tratamento eletivo: o tratamento deve ser adiado. Paciente com suspeita para COVID-19 e tratamento eletivo: o tratamento deve ser adiado. Deve-se orientar o paciente a fazer isolamento domiciliar imediatamente e procurar o órgão de saúde caso os sintomas se agravem (ZHANG, 2020).

Paciente sem suspeita para COVID-19 e tratamento de urgência / emergência: o tratamento odontológico deve ser realizado com precaução padrão e adicional para toda a equipe, considerando todos os pacientes potencialmente infectados. Fazer o descarte de resíduos em lixo apropriado, assim como desinfecção de todas as superfícies ao final do atendimento. Realizar o suporte necessário após o atendimento por telefone, de forma a evitar contato com o paciente (ZHANG, 2020).

\section{MEDIDAS DE CONTROLE E PREVENÇÃO NO ATENDIMENTO CLÍNICO}

Lavagem das mãos: Através do contato das mãos com superfícies contaminadas é possível a propagação do vírus através do contato com os olhos, boca e nariz, sendo uma importante via de transmissão. Sendo assim, a higienização das mãos com água e sabão de 20 a 30 segundos deve ser feita antes e após o atendimento. Se as mãos estiverem livres de sujidades, recomenda-se pela OMS o uso de álcool em gel a 70\%. A secagem das mãos deve ser feita com papel toalha descartável. Lembrando sempre de retirar todos os adereços como anel, pulseira e relógio (MONTE et al., 2020).

Desinfecção de superfícies: existem relatos de permanência do vírus SARS-CoV-2 em superfícies de diversas naturezas, a desinfecção deve ser feita antes e depois dos procedimentos clínicos fazendo uso de hipoclorito de sódio ou peróxido de hidrogênio e álcool $70 \%$. Como também o uso de barreiras de proteção que devem ser descartadas ao término de cada atendimento (MONTE et al., 2020).

Equipamentos de Proteção Individual (EPI): o uso do equipamento de proteção individual deve ser feito criteriosamente para todos os atendimentos, tais como jaleco, máscara, gorro, óculos (mesmo se fizer uso de óculos de gral), luva e protetores de face. Toda a retirada do EPI deve ser feita antes de sair do consultório, de modo a garantir a diminuição de contaminação cruzada no ambiente clinico (XIAN et al, 2020).

Uso de máscara N95 (ou equivalente): as 
mascaras N95 ou equivalentes apresentam uma melhor proteção em procedimentos que tenham como resultante a produção de aerossol no atendimento odontológico. $\mathrm{O}$ descarte das mascaras deve seguir a orientação do serviço de saúde (ZHANG, 2020).

Uso de capote ou avental: o material utilizado na confecção deve ser de boa qualidade, proporcionando barreira antimicrobiana (Teste de Eficiência de Filtração Bacteriológica - BFE). Deve ser usado fechado, com mangas longas, punho de elástico e abertura posterior (ZHANG, 2020).

Protetor facial: o equipamento deve ser de uso pessoal para cada profissional devendo cobrir a frente e as laterais do rosto sendo uma importante barreira contra o aerossol produzido no atendimento clinico. Deve ser limpo e desinfetado com álcool $70 \%$ logo após o uso (ZHANG, 2020).

Bochecho antes do procedimento: o uso de peróxido de hidrogênio a $1 \%$ e Iodopovidona a $0,2 \%$ mostraram-se eficazes. Isolamento absoluto minimiza a produção de aerossol contaminado pelo vírus. A remoção manual do tecido cariado deve ser uma forma opcional de promover um tratamento restaurador de modo que diminua a produção de aerossol no atendimento odontológico (XIAN et al, 2020).

Sistema antirretorno no uso de instrumentos rotatórios: é recomendado uso de motores com válvulas antirrefluxo para minimizar a possibilidade de infecção cruzada, como também a esterilização das peças de mão através de autoclave (MONTE et al, 2020).

\section{DISCUSSÃO}

Segundo QUN et al. (2020), mesmo com a tomada de precauçoes da organização mundial de saúde em dezembro 2019, os casos aumentaram de forma alarmante, tornando-se um assunto de interesse mundial. Observando os dados atualizados diariamente por WHO (2020), o numero de casos confirmados e mortes se mostram em uma proporção cada vez maior.

OLIVEIRA et al. (2020), traz em sua pesquisa dados sobre a capacidade do vírus Sars-Cov-2 permanecer viável por periodos prolongados sobre superfícies de naturezas diferentes. TUÑAS et al. (2020) relata que é possivel a contaminação do individuo que toca essas superficies contamidas e leva a mão aos olhos, boca e nariz podendo assim ser feita a disseminação da doença.

A manifestação clinica da doença COVID-19 pode apresentar sintomas semelhantes aos de uma gripe comum, fazendo-se necessário o conhecimento na observação dos sintomas que variam de ausência de sintomas a manifestações agudas. Como também a necessidade de realizar testes para comprovar de fato a infecção (OLIVEIRA et al., 2020).
Os achados de PEREIRA, et al. (2020), relatam que os aerossóis e gotículas produzidos no atendimento odontológico são um fator primordial para a disseminação do vírus causador da doença COVID-19 através de partículas contaminadas com fluidos orgânicos do paciente. O estudo de XIAN et al. (2020), relata que é evidente a produção de uma nuvem de aerossol durante o procedimento odontológico, causada por instrumentos rotatórios e jato de água, sendo assim, esse evento é apontado como grande potencial de disseminação do vírus.

XIAN et al. (2020), relata que o atendimento odontológico eletivo não emergêncial recebeu ordem de suspensão. MONTE et al. (2020), elucida que algumas pessoas infectadas não desenvolvem os sintomas. O que torna necessário o reforçamento da pratica da biossegurança no atendimento odontológico devido a dificuldade no reconhecimento de casos.

Concomitantemente com os achados anteriores, ZHANG (2020) enfatiza que existe a necessidade de uma rigorosa prática de biossegurança. Segundo TUÑAS et al., (2020) pessoas infectadas, que ainda não apresentam sintomas se tornam forte fonte de infecção, expondo a equipe odontológica ao risco de infecção ao COVID-19.

Faz-se necessário ter conhecimento sobre o histórico dos últimos dias do paciente, bem como sua condição de saúde e assim ser possível ou não prosseguir com o atendimento clínico. Toda a equipe odontológica se torna vulnerável aos microrganismos patogênicos quando medidas de segurança não são adotadas.

\section{CONCLUSÕES}

O vírus causador da doença COVID-19 se transformou em uma pandemia na saúde pública de interesse mundial. A transmissão é possível através do contato com superfícies infectadas com os fluidos do individuo infectado, incluindo saliva e aerossol. Pessoas assintomáticas não mostram sinais clínicos da doença, mas, mesmo assim, podem propagar o vírus. O consultório odontológico está indicado entre os principais locais possíveis de transmissão entre paciente e profissional. Até o momento dessa pesquisa, o tratamento da doença ainda é desconhecido, o que reforça ainda mais as práticas de prevenção através da biossegurança. Consultas odontológicas eletivas e procedimentos não essenciais devem ser adiados, sendo viáveis apenas atendimentos de urgência e emergência. A revisão demonstrou que, em momentos de surtos de doenças, surgem novos desafios, ao qual, a equipe de saúde bucal deve responder com maior cuidado, buscando informações atualizadas. Os dados apresentados nesse artigo estão em constante atualização, fazendo-se necessário a continuidade em pesquisas para o levantamento de novas discussões, tanto 
para gerar mais dados e serem fonte de pesquisa, como para o conhecimento geral sobre o assunto, sendo possível reconhecer os riscos que desafiam a segurança no atendimento odontológico.

\section{REFERÊNCIAS}

ANVISA- Agência de Vigilância Sanitária. Orientações para serviço de saúde: medidas de prevenção e controle que devem ser adotadas durante a assistência aos casos suspeitos ou confirmados de infecção pelo novo coronavírus (SARS-COV-2). Portal ANVISA. 08 de maio de 2020. Disponível em $<$ http://portal.anvisa.gov.br/documents/33852/271858/No ta+T\%C3\%A9cnica+n+04-2020+GVIMS-GGTESANVISA/ab598660-3de4-4f14-8e6f-b9341c196b28 >

Acesso em 07/09/2020

GIUDICE, R. L. The Severe Acute Respiratory Syndrome Coronavirus-2 (SARS CoV-2) in Dentistry. Management of Biological Risk in Dental Practice. International Journal of Environ Res Public Health. D.O.I.: 10.3390/ijerph17093067. 17 de maio de 2020. Disponível $\mathrm{em}$ <https://www.ncbi.nlm.nih.gov/pmc/articles/PMC724687 9/> Acesso em 30/06/2020

GE, Z.Y.; YANG L. M.; XIA, J.J.; FU X. H.; ZHANG Y. $Z$. Possible aerosol transmission of COVID-19 and special precautions in dentistry. JZUSB-Jornal of Zhejiang University SCIENCE B. DOI: 10.1631/jzus.B2010010. 21 de maio de 2020. Disponível em <https://www.ncbi.nlm.nih.gov/pmc/articles/PMC708948 1/> Acesso em 30/06/2020

RODRÍGUEZ, E. A. S. et al. COVID-19 and Dentistry: a Review of Recommendations and Perspectives for Latin America. International journal of odontostomatology. vol.14 n. 3 Temuco 21 de abr. de 2020 .

Disponível

em $<$ https://scielo.conicyt.cl/scielo.php?script=sci_arttext\&p $\underline{\mathrm{id}=\mathrm{S} 0718-381 \mathrm{X} 2020000300299 \& \text { lang=pt }>\text { Acesso em }}$ $30 / 06 / 2020$

MONTE, L. M. et al. Complicações atípicas e características clínico - epidemiológicas do COVID19:uma revisão integrativa. Revista Eletrônica Acervo Saúde. 14 de maio de 2020. DOI:https://doi.org/10.25248/reas.e3699.2020.

Disponível em:

https://www.acervomais.com.br/index.php/saude/article/ view/3699/1937>. Acesso em 30/06/2020
OLIVEIRA, J. J. M. et al. O impacto do coronavírus (covid-19) na prática odontológica: desafios e métodos de prevenção. Revista Eletrônica Acervo Saúde.12 de jun de

2020 .

DOI: https://doi.org/10.25248/reas.e3487.2020.

Disponível

em: <https://www.acervomais.com.br/index.php/saude/article /view/3487/2094> Acesso em 30/06/2020

PEREIRA, L. J.; PEREIRA, C. V.; MURATA, R. M.; PARDI, V.;DOURADO,S. M. P. Biological and Social Aspects of Coronavirus Disease 2019 (COVID-19) Related to Oral Health. Brazilian Oral Research, 08 de maio de 2020. DOI: 10.1590/1807-3107bor-2020. vol34.0041. Disponível em < https://pubmed.ncbi.nlm.nih.gov/32401931/> Acesso em $30 / 06 / 2020$

QUN, L.; MED, M.; XUHU, G. et al. Early Transmission dynamics in Wuhan, China, of novel coronavirus-infected pneumonia. The new england journal of medicine, China, 26 de mar. de 2020. VOL. 382 NO. 13. DOI: 10.1056/NEJMoa2001316.

Disponível

em:

<https://www.nejm.org/doi/full/10.1056/NEJMoa200131 6). Acesso em: 14 de maio de 2020 .

TUÑAS, I. T. C.; SILVA, E. T.; SANTOS, S. B.; MAIA, K. D.; JÚNIOR, G. O. S. Doença pelo Coronavírus 2019 (COVID-19): Uma Abordagem Preventiva para Odontologia. Revista brasileira de odontologia. $16 \mathrm{de}$ mar. de 2020. Vol.77. DOI:10.18363/rbo.v77.2020.e1766. Disponível

em: <http://revista.aborj.org.br/index.php/rbo/article/view/17 76/pdf>. Acesso em 24/05/2020

WHO- World Health Organization. WHO Coronavirus Disease (COVID-19) Dashboard. World Health Organization. 15 de out. de 2020. Disponível em:< https://covid19.who.int/> Acesso em: 15/10/2020

XIAN, P. et al. Transmission routes of 2019-nCoV and controls in dental practice. International Journal of Oral Science, China, 03 de mar. De 2020. DOI: doi.org/10.1038/s41368-020-0075-9. Disponível em: 
$<$ https://www.nature.com/articles/s41368-020-0075-

9.pdf>. Acesso em 24/05/2020.

ZHANG, W.; JIANG, X. Measures and suggestions for the prevention and control of the novel coronavirus in dental institutions. FOMM. 24 de Dez de 2020. DOI: 10.21037/fomm.2020.02.01

Disponível em

<http://fomm.amegroups.com/article/view/36147/html > Acesso em 26/05/2020

ZHU, N. et al. A novel coronavirus from patients with pneumonia in China, 2019. The new england journal of medicine, China, 20 de Fev. de 2020, Vol. 382 No 8. pp. 727-733. DOI: 10.1056/NEJMoa2001017. Disponível em:

https://www.nejm.org/doi/full/10.1056/NEJMoa2001017 >. Acesso em 14 de maio de 2020. 